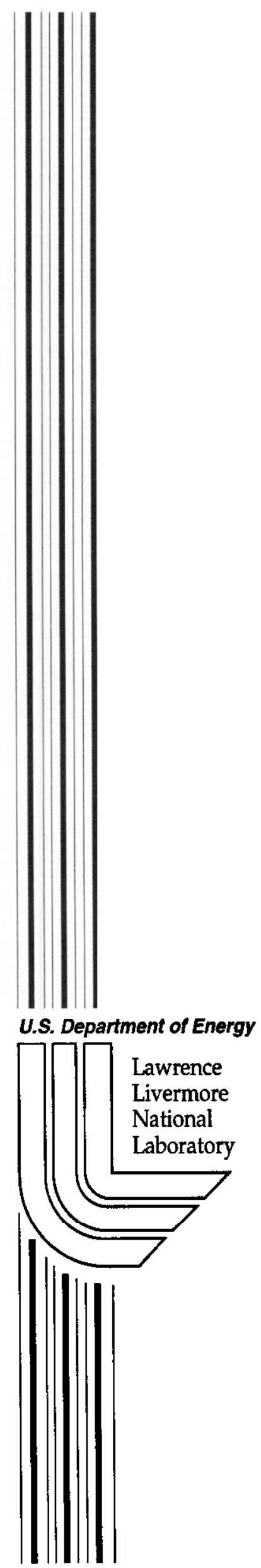

\title{
Newtonian Flow in Bulk Amorphous Alloys
}

J. Wadsworth and T.G. Nieh

This article was submitted to

Materials Research Society Fall 1999 Meeting, Boston, MA, November 29 - December 3, 1999

\section{September 27, 2000}




\section{DISCLAIMER}

This document was prepared as an account of work sponsored by an agency of the United States Government. Neither the United States Government nor the University of California nor any of their employees, makes any warranty, express or implied, or assumes any legal liability or responsibility for the accuracy, completeness, or usefulness of any information, apparatus, product, or process disclosed, or represents that its use would not infringe privately owned rights. Reference herein to any specific commercial product, process, or service by trade name, trademark, manufacturer, or otherwise, does not necessarily constitute or imply its endorsement, recommendation, or favoring by the United States Government or the University of California. The views and opinions of authors expressed herein do not necessarily state or reflect those of the United States Government or the University of California, and shall not be used for advertising or product endorsement purposes.

This is a preprint of a paper intended for publication in a journal or proceedings. Since changes may be made before publication, this preprint is made available with the understanding that it will not be cited or reproduced without the permission of the author.

This report has been reproduced

directly from the best available copy.

Available to DOE and DOE contractors from the

Office of Scientific and Technical Information

P.O. Box 62, Oak Ridge, TN 37831

Prices available from (423) 576-8401

http://apollo.osti.gov/bridge/

Available to the public from the

National Technical Information Service

U.S. Department of Commerce

5285 Port Royal Rd.,

Springfield, VA 22161

http://www.ntis.gov/

OR

Lawrence Livermore National Laboratory

Technical Information Department's Digital Library

http://www.llnl.gov/tid/Library.html 


\title{
NEWTONIAN FLOW IN BULK AMORPHOUS ALLOYS
}

\author{
J. WADSWORTH AND T.G. NIEH \\ Lawrence Livermore National Laboratory, P.O. Box 808, Livermore, CA 94551 \\ Presented at the 1999 MRS Fall Meeting, November 29-December 3, 1999, Boston, MA
}

\begin{abstract}
Bulk amorphous alloys have many unique properties, e.g., superior strength and hardness, excellent corrosion resistance, reduced sliding friction and improved wear resistance, and easy formability in a viscous state. These properties, and particularly easy formability, are expected to lead to applications in the fields of near-net-shape fabrication of structural components. Whereas large tensile ductility has generally been observed in the supercooled liquid region in metallic glasses, the exact deformation mechanism, and in particular whether such alloys deform by Newtonian viscous flow, remains a controversial issue. In this paper, existing data are analyzed and an interpretation for the apparent controversy is offered. In addition, new results obtained from an amorphous alloy (composition: $\mathrm{Zr}-10 \mathrm{Al}-5 \mathrm{Ti}-17.9 \mathrm{Cu}-14.6 \mathrm{Ni}$, in at. \%) are presented. Structural evolution during plastic deformation is particularly characterized. It is suggested that the appearance of non-Newtonian behavior is a result of the concurrent crystallization of the amorphous structure during deformation.
\end{abstract}

\section{INTRODUCTION}

Metallic glasses fabricated by rapid quenching from the melt were first discovered in 1960 [1]. Due to the high quench rate requirements $\left(10^{4}-10^{6} \mathrm{~K} / \mathrm{s}\right)$, only thin ribbons and sheets with a thickness less than $0.1 \mathrm{~mm}$ could be fabricated. One of the most important recent developments in the synthesis of amorphous materials is the discovery that certain metallic glasses can be fabricated from the liquid state at cooling rates of the order of $10 \mathrm{~K} / \mathrm{s}$. This enables the production of bulk amorphous alloys with a thickness of $\sim 10 \mathrm{~mm}$. These bulk amorphous alloys have many potential applications resulting from their unique properties, e.g., superior strength and hardness [2], excellent corrosion resistance [3], reduced sliding friction and improved wear resistance [4], and easy forming in a viscous state [5-7]. These properties, and particularly easy forming in a viscous state, should lead to applications in the fields of near-net-shape fabrication of structural/functional components.

The mechanical behavior of metallic glasses is characterized by either inhomogeneous or homogeneous deformation. Inhomogeneous deformation usually occurs when a metallic glass is deformed at low temperature (e.g. room temperature) and is characterized by the formation of localized shear bands, followed by the rapid propagation of these bands, and sudden fracture. Thus, when a metallic glass is deformed under tension it exhibits very limited macroscopic plasticity. It is pointed out that, despite a limited macroscopic plasticity, local strain within these shear bands can be, sometimes quite significant (about 10). These bands are typically 20-30 $\mathrm{nm}$ in width and have not yet been microscopically examined [8], although some observations indicated possible crystallization [9]. Whereas there exist many different views on inhomogeneous deformation in metallic glasses (e.g., free-volume model $[10,11]$ and dislocation theory [12]), there is still no universal agreement. This paper is to address only homogeneous deformation.

Homogeneous deformation in metallic glasses usually takes place at about $0.70 \mathrm{~T}_{\mathrm{g}}[11]$ above which metallic glasses exhibit significant plasticity. It is pointed out that the transition temperature $\mathrm{T}_{\mathrm{tr}}$ from inhomogeneous to homogeneous deformation (or brittle-to-ductile transition) is strongly dependent upon strain rate. For example, $\mathrm{T}_{\mathrm{tr}}$ for $\mathrm{Zr}_{65} \mathrm{Al}_{10} \mathrm{Ni}_{10} \mathrm{Cu}_{15}$ alloy is about $533 \mathrm{~K}$ (corresponds to $0.82 \mathrm{~T}_{\mathrm{g}}$ ) at $5 \times 10^{-4} \mathrm{~s}^{-1}$, but it is $652 \mathrm{~K}$ (corresponds to $1.0 \mathrm{~T}_{\mathrm{g}}$ ) at $5 \times 10^{-2} \mathrm{~s}^{-1}$ [6]. The strain rate dependence of $\mathrm{T}_{\mathrm{tr}}\left(480-525 \mathrm{~K} ; 0.61-0.75 \mathrm{~T}_{\mathrm{g}}\right)$ has also been demonstrated in $\mathrm{Fe}_{40} \mathrm{Ni}_{40} \mathrm{~B}_{20}$ [13]. These results suggest that homogeneous deformation is associated with certain rate (or diffusional relaxation) processes. For the purpose of discussion, we divide the homogeneous deformation of metallic glasses into three regions, according to testing temperatures. 
$\mathbf{T}<\mathbf{T}_{\mathbf{g}}$

Mulder et al [13], in a study of the deformation of $\mathrm{Fe}_{40} \mathrm{Ni}_{40} \mathrm{~B}_{20}$ metallic glass in tension at elevated temperatures, found that the transition temperature from inhomogeneous to homogeneous deformation is about $480-525 \mathrm{~K}\left(0.68-0.75 \mathrm{~T}_{\mathrm{g}}\right)$, as predicted by a free volume model [11]. The also conducted creep experiments at temperatures $(523-548 \mathrm{~K})$ below the glass transition temperature with a relatively high stress $(>1.0 \mathrm{GPa})$. Experimental results showed that the stress exponent was rather high $(n=8.5)$. The activation energy was determined to be between 250 and $280 \mathrm{~kJ} / \mathrm{mol}$, which is similar to that for eutectic crystallization below the glass transition temperature.

Taub and Luborsky [14] also conducted tensile creep experiments on amorphous $\mathrm{Fe}_{40} \mathrm{Ni}_{40} \mathrm{P}_{14} \mathrm{~B}_{6}$ ribbons. They found that within the temperature range of $383-582 \mathrm{~K}\left(\mathrm{~T}_{\mathrm{g}}=663 \mathrm{~K}\right.$ and $\mathrm{T}_{\mathrm{x}}=673 \mathrm{~K}$, where $\mathrm{T}_{\mathrm{x}}$ is the crystallization temperature) and at a constant tensile stress of $312 \mathrm{MPa}$ the strain rate varies inversely with time but only after an initial transition. They also performed stress relaxation experiments and showed that the stress dependence of the strain rate obey a hyperbolic sine relationship (nonlinear), consistent with transition state theory [15]. To further reconcile all data, including those from the initial transition, a threshold stress $(=39 \pm 4 \mathrm{MPa})$ was introduced into the formulation, although the physical meaning of the threshold stress was unclear.

Most recently, Kawamura et al [6] studied the high-temperature deformation properties of a $\mathrm{Zr}_{65} \mathrm{Al}_{10} \mathrm{Ni}_{10} \mathrm{Cu}_{15}$ metallic glass $\left(\mathrm{T}_{\mathrm{g}}=652 \mathrm{~K}, \mathrm{~T}_{\mathrm{x}}=757 \mathrm{~K}\right)$ with a wide range of $\Delta \mathrm{T}\left(=\mathrm{T}_{\mathrm{g}}-\mathrm{T}_{\mathrm{x}}\right)$ produced by a meit spinning method. They found that, within $\mathrm{T}_{t r}<\mathrm{T}<\mathrm{T}_{\mathrm{g}}$, the alloy has a low strain rate sensitivity value $(\mathrm{m}<0.25)$ and the tensile elongation is also low $(<100 \%)$. Similar observations were also made in $\mathrm{Pd}_{40} \mathrm{Ni}_{40} \mathrm{P}_{20}$ metallic glasses, and results showed that at a test temperature of $560 \mathrm{~K}\left(\mathrm{~T}_{\mathrm{g}}=578-597 \mathrm{~K}\right)$, the alloy exhibited a low strain rate sensitivity of only 0.20 and tensile elongation $<50 \%$.

From the above results, we may conclude that homogeneous deformation of metallic glasses at temperatures below $\mathrm{T}_{\mathrm{g}}$ are characterized by a low strain rate sensitivity (i.e. high stress exponent) and ductility $(<100 \%)$. This is attributable to the fact that structural relaxation and recovery are still difficult as a result of sluggish diffusion in this temperature range.

\section{$\mathbf{T}_{\mathrm{g}}<\mathrm{T}<\mathrm{T}_{\mathrm{x}}$ (supercooled liquid region)}

As early as 1980, Homer and Eberhardt [16] reported the observation of superplasticity in amorphous Pd 78.1 Fe ${ }_{5.1} \mathrm{Si}_{16.8}$ ribbons $\left(\mathrm{T}_{\mathrm{g}}=668 \mathrm{~K}, \mathrm{~T}_{\mathrm{x}}=683 \mathrm{~K}\right)$ during non-isothermal creep experiments. In the experiments, test samples were rapidly heated to the maximum temperature of $698 \mathrm{~K}$ under a constant load (range: 25-150 MPa). The resulted creep rate was rather high; for example, an applied stress of $150 \mathrm{MPa}$ produced a creep rate of $0.5 \mathrm{~s}^{-1}$. The strain rate sensitivity value was estimated to be about one, suggesting possible Newtonian flow. Since $698 \mathrm{~K}$ is higher than $\mathrm{T}_{\mathrm{x}}$, a dispersion of $0.4 \mu \mathrm{m}$ grains in the amorphous matrix was observed in the test samples after superplastic deformation. It is noted that slow heating during creep test resulted in the disappearance of superplasticity. This is apparently caused by easy crystallization in the alloy, as indicated by a narrow $\Delta \mathrm{T}(=15 \mathrm{~K})$.

Zelenskiy et al. [17] studiēd the formability of amorphous $\mathrm{C}_{66} \mathrm{Fe}_{7} \mathrm{Ni}_{13} \mathrm{Si}_{7} \mathrm{~B}_{5}\left(\mathrm{~T}_{\mathrm{g}}=836 \mathrm{~K}, \mathrm{~T}_{\mathrm{x}}=856 \mathrm{~K}\right)$ at temperatures between 773 and $913 \mathrm{~K}$. They observed large tensile ductility at a relatively fast strain rate of $10^{-2} \mathrm{~s}^{-1}$ within $823-853 \mathrm{~K}$ (in the supercooled liquid region). Specifically, the maximum elongation of $180 \%$ was recorded at a corresponding minimum stress of about $150 \mathrm{MPa}$. However, strain rate sensitivity was not measured. TEM microstructural examinations indicated that $853 \mathrm{~K}$ annealing produces nanometer grains $(\sim 50-70$ $\mathrm{nm}$ ) in the alloy. From these results, the authors argued that the presence of a large amount of grain/amorphous matrix interfacial area is necessary for the observed superplasticity. However, we want to point out that this may not be true. In fact, several experiments indicated a reduced ductility in the presence of nanograins [6, 16]. A recent study of Busch et al [18] also showed that the viscosity of a metallic glass increases sharply once the temperature is above the crystallization temperature. As expected, an increase in viscosity leads to an increasing resistance to plastic flow and, thus, a decrease in ductility.

To further understand superplasticity and extended plasticity in metallic glasses, Khonik and Zelenskiy [19] analyzed available mechanical data from fifteen different metallic glasses, including both metal-metal and metalmetalloid systems. They made several important observations. First, superplasticity occurs in alloys with a large $\Delta \mathrm{T}$, typically about several tens degrees. The larger is $\Delta \mathrm{T}$, the larger is the tensile elongation, provided tests were conducted in the supercooled liquid region. This indicates the importance of thermal stability of a metallic glass during superplastic deformation. They noticed also that a faster heating rate usually produced a larger elongation. Apparently, this is associated with structural stability since slower heating results in an earlier crystallization.

In studying the formability of a Las5 $\mathrm{Al}_{25} \mathrm{Ni}_{20}$ alloy, Kawamura et al [7] reported that the alloy in the supercooled liquid range $(480-520 \mathrm{~K})$ behaves like a Newtonian fluid, i.e., $m=1$. A tensile elongation of over $1,800 \%$ was recorded at $503 \mathrm{~K}$ at a strain rate of $2 \times 10^{-1} \mathrm{~s}^{-1}$. The glassy solid below the glass transition temperature exhibited non-Newtonian viscosity, and the supercooled liquid revealed a Newtonian viscosity but changed to non-Newtonian with increasing strain rate. The elongation was reduced by the transition to nonNewtonian viscosity and crystallization. However, a careful examination of their stress-strain rate data indicated that the strain rate sensitivity tends to decrease to less than one when testing temperature (e.g. 510, 520K) 
approaches $T_{x}$. Again, this is probably associated with a partial crystallization in amorphous structure during testing.

Kawamura et al [6] recently studied the high-temperature deformation of a $\mathrm{Zr}_{65} \mathrm{Al}_{10} \mathrm{Ni}_{10} \mathrm{Cu}_{15}$ metallic glass with a wide range of $\Delta T\left(T_{g}=652 K, T_{x}=757 K\right)$. In the supercooled liquid region, they found that plastic flow were strongly dependent on strain rate and the strain rate sensitivity value exceeded 0.8 , but less than one. The high strain rate sensitivity produces a corresponding high tensile elongation. For example, a tensile elongation of $340 \%$ was obtained at a strain rate of $5 \times 10^{-2} \mathrm{~s}^{-1}$ and at $673 \mathrm{~K}$. However, a true Newtonian behavior $(\mathrm{m}=1)$ was not observed in the alloy.

To further investigate superplasticity in metallic glass systems, Kawamura et al [6] tested a $\mathrm{Pd}_{40} \mathrm{Ni}_{40} \mathrm{P}_{20}$ alloy prepared by rapid solidification. Within $560-620 \mathrm{~K}$, the alloy exhibits a similar deformation behavior to that of $\mathrm{Zr}_{65} \mathrm{Al}_{10} \mathrm{Ni}_{10} \mathrm{Cu}_{15}$, namely, a high-strain-rate-sensitivity value accompanied by extended tensile ductility in the supercooled liquid region $\left(\mathrm{T}_{\mathrm{g}}=578-597 \mathrm{~K}, \mathrm{~T}_{\mathrm{x}}=651 \mathrm{~K}\right)$. In contrast to $\mathrm{Zr}_{65} \mathrm{Al}_{10} \mathrm{Ni}_{10} \mathrm{Cu}_{15}$ which is non-Newtonian, $\mathrm{Pd}_{40} \mathrm{Ni}_{40} \mathrm{P}_{20}$ can behave like a true Newtonian fluid (i.e. $\mathrm{m}=1$ ) under appropriate testing conditions. The difference may be associated with the fact that $\mathrm{Pd}_{40} \mathrm{Ni}_{40} \mathrm{P}_{20}$ is thermally more stable than $\mathrm{Zr}_{65} \mathrm{Al}_{10} \mathrm{Ni}_{10} \mathrm{Cu}_{15}$ in the supercooled liquid state, as pointed out by Kawamura et al [6]. $\left(\triangle \mathrm{T}=72\right.$ and $100 \mathrm{~K}$ for $\mathrm{Zr}_{65} \mathrm{Al}_{10} \mathrm{Ni}_{10} \mathrm{Cu}_{15}$ and $\mathrm{Pd}_{40} \mathrm{Ni}_{40} \mathrm{P}_{20}$, respectively.) Therefore, during high-temperature deformation, $\mathrm{Pd}_{40} \mathrm{Ni}_{40} \mathrm{P}_{20}$ can still retain its amorphous state, whereas crystallization may have already taken place in $\mathrm{Zr}_{65} \mathrm{Al}_{10} \mathrm{Ni}_{10} \mathrm{Cu}_{15}$. This is indirectly indicated by the fact that the viscosity of $\mathrm{Pd}_{40} \mathrm{Ni}_{40} \mathrm{P}_{20}$ is about one order of magnitude lower than that of $\mathrm{Zr}_{65} \mathrm{Al}_{10} \mathrm{Ni}_{10} \mathrm{Cu}_{15}$.

Thus, at $T_{g}<T<T_{x}$, large tensile ductility can be obtained from metallic glasses with large $\Delta T$. The maximum ductility is expected to occur at a temperature near $T_{\mathbf{x}}$, where the flow stress (or viscosity) is low, and high strain rates at which the alloy can retain its amorphous structure during deformation. For convenience, the above data are summarized in Table 1.

Table 1 Summary of the deformation data of some metallic glasses in the supercooled liquid region

\begin{tabular}{|l|c|c|c|c|c|}
\hline \multicolumn{1}{|c|}{ Alloys } & $\mathrm{T}_{\mathbf{g}}$ & $\mathrm{T}_{\mathbf{x}}$ & $\mathrm{m}$ & Elongation & Ref. \\
\hline $\mathrm{Pd}_{78.1} \mathrm{Fe}_{5.1} \mathrm{Si}_{16}$ & $668 \mathrm{~K}$ & $683 \mathrm{~K}$ & $\sim 1.0$ & N/A & {$[16]$} \\
\hline $\mathrm{C}_{66} \mathrm{Fe}_{7} \mathrm{Ni}_{13} \mathrm{Si}_{7} \mathrm{~B}_{5}$ & $836 \mathrm{~K}$ & $856 \mathrm{~K}$ & N/A & 180 & {$[17]$} \\
\hline $\mathrm{La}_{55} \mathrm{Al}_{25} \mathrm{Ni}_{20}$ & $480 \mathrm{~K}$ & $520 \mathrm{~K}$ & 1 & 1,800 & {$[7]$} \\
\hline $\mathrm{Zr}_{65} \mathrm{Al}_{10} \mathrm{Ni}_{10} \mathrm{Cu}_{15}$ & $652 \mathrm{~K}$ & $757 \mathrm{~K}$ & $>0.8$ & 340 & {$[6]$} \\
\hline $\mathrm{Pd}_{40} \mathrm{Ni}_{40} \mathrm{P}_{20}$ & $578-597 \mathrm{~K}$ & $651 \mathrm{~K}$ & 1.0 & N/A & {$[6]$} \\
\hline $\mathrm{Ni}_{77.5} \mathrm{Si}_{7.5} \mathrm{~B}_{15}$ & N/A & N/A & 1.09 & N/A & {$[20]$} \\
\hline
\end{tabular}

$\mathbf{T}_{\mathbf{x}}<\mathbf{T}$

At a temperature higher than $T_{x}$, metallic glass alloys are readily crystallized and form nanocrystalline structures. Whereas there are some data on plasticity of nanocrystalline solids at temperatures much greater than $\mathrm{T}_{\mathrm{x}}$, there exist only limited information on the mechanical behavior of metallic glasses at temperatures slightly above $T_{x}$.

Ashdown et al [21] studied the superplastic behavior of a crystallized Fe-Cr-Ni-B glassy alloy. By controlling crystallization, a material with a grain size of $0.2 \mu \mathrm{m}$ was produced. Tensile elongation of over $200 \%$ was readily obtained from the material tested at strain rates of over $10^{-2} \mathrm{~s}^{-1}$ and at a temperature as low as $1073 \mathrm{~K}$; the maximum elongation of $450 \%$ was recorded at $1273 \mathrm{~K}$ and a strain rate of $10^{-2} \mathrm{~s}^{-1}$. These results are in accordance with the conventional fine-grained superplasticity.

Brandt et al [22] also studied the superplastic behavior of a microcrystalline $(0.5 \mu \mathrm{m}) \mathrm{Ni}_{78} \mathrm{Si}_{8} \mathrm{~B}_{14}$ produced by annealing amorphous samples at $1073 \mathrm{~K}$. The material contains equiaxed $\mathrm{Ni}_{3} \mathrm{~B}$ and $\mathrm{Ni}_{3} \mathrm{Si}$ grains and showed a tensile elongation of over $120 \%$ at $823-1023 \mathrm{~K}$. The strain rate sensitivity value was essentially constant $(m=0.85)$ over a wide range of strain rate $\left(10^{-6}\right.$ to $\left.10^{-2} \mathrm{~s}^{-1}\right)$ and the activation energy was $72.4 \mathrm{~kJ} / \mathrm{mol}$. These results indicated the occurrence of conventional fine-grained superplasticity.

Using a similar technique, Wang and coworkers [23, 24] crystallized an amorphous $\mathrm{Ni}_{80} \mathrm{P}_{20}$ alloy at $603 \mathrm{~K}$. The crystallized alloy was nanocrystalline, consisting of $80 \mathrm{vol} \% \mathrm{Ni}_{3} \mathrm{P}$ and $20 \mathrm{vol} \% \mathrm{Ni}$. Creep experiments were subsequently conducted at $543-583 \mathrm{~K}$ on the crystallized samples and the data showed a stress exponent of 1.2 $(m=0.8)$ and activation energy $68 \mathrm{~kJ} / \mathrm{mol}$. From these data, the authors argued that Coble creep was responsible for the deformation.

Most recently, two submicrocrystalline bulk alloys, Al-14mass\% Ni-14mass\% Misch Metal [25] and Mg8.3wt\%Al-8.1 wt\%Ga [26], were produced by the extrusion of rapidly solidified amorphous powders. The grain sizes of the extruded $\mathrm{Al}$ and $\mathrm{Mg}$ alloys were 0.1 and $0.6 \mu \mathrm{m}$, respectively. Resulting from fine grain sizes, both alloys were highly superplastic (elongation $=600 \%$ for $\mathrm{Al}$ and $>1000 \%$ for $\mathrm{Mg}$ ) and the strain rates at which superplasticity took place were also high $\left(>10^{-2} \mathrm{~s}^{-1}\right)$. 
The above experiments were all carried out at temperature much higher than $T_{x}$. In fact, the testing temperatures were sometimes close to $T_{m}$, the melting point of the alloys. At these temperatures material are no longer amorphous, but rather nanocrystalline or even microcrystalline, depending upon the thermal stability of the alloys. Conventional mechanisms for high temperature deformation, and particularly superplastic deformation, are expected to prevail.

In summary, for homogeneous deformation in metallic glasses, large tensile ductility can generally be obtained in the supercooled liquid. The exact deformation mechanism, however, and in particular whether an alloy deforms by Newtonian viscous flow or not remains a controversial issue. The purpose of this paper is to report an example of non-Newtonian behavior in a cast amorphous $\mathrm{Zr}-10 \mathrm{Al}-5 \mathrm{Ti}-17.9 \mathrm{Cu}-14.6 \mathrm{Ni}$ alloy in the supercooled liquid region.

\section{EXPERIMENTS}

The material used in the present study has a composition of $\mathrm{Zr}-10 \mathrm{Al}-5 \mathrm{Ti}-17.9 \mathrm{Cu}-14.6 \mathrm{Ni}$. Zone-purified $\mathrm{Zr}$ bars (containing 12.3 appm $\mathrm{O}$ and 10 appm $\mathrm{Hf}$ ), together with pure metal elements, were used as charge materials. The alloys were prepared by arc melting in inert gas, followed by drop casting into 7.0 -mm-diameter by $7.2 \mathrm{~cm}$ long $\mathrm{Cu}$ molds at Oak Ridge National Laboratory. The details of fabrication of the alloy have been described previously [2]. Differential scanning calorimetry was used to characterize the thermal properties of the alloy. The temperatures for the onset and end of glass transition, and the crystallization temperature $\left(T_{x}\right)$, have been previously measured using differential scanning calorimetry (DSC) [27]; specifically, these temperatures are 631, 705 , and $729 \mathrm{~K}$, respectively, at a heating rate of $20 \mathrm{~K} / \mathrm{min}$.

Tensile sheet specimens were fabricated from the as-cast material by means of electrical discharge machining. They had a gage length of $4.76 \mathrm{~mm}$, a thickness of $1.27 \mathrm{~mm}$ and a width of $1.59 \mathrm{~mm}$, as shown in Fig. 1. Tensile tests were conducted using an Instron machine equipped with an air furnace. Because of structural instability during testing of samples at high temperatures, the heating rate must be rapid to minimize crystallization. Typically, the heating-plus-holding time prior to testing was about 25 minutes. For example, for a test at $683 \mathrm{~K}$ at a constant strain rate of $10^{-2} \mathrm{~s}^{-1}$, the temperature profile was: $578 \mathrm{~K}(5 \mathrm{~min}), 644 \mathrm{~K}(10 \mathrm{~min}), 670 \mathrm{~K}(15 \mathrm{~min}), 680 \mathrm{~K}$ $(20 \mathrm{~min})$, and $683(47 \mathrm{~min})$. Constant strain rate tests were performed at a constant strain rate of $10^{-2} \mathrm{~s}^{-1}$ with a computer-controlled machine within a temperature range of 663-743K. To measure strain rate sensitivity exponents, both strain rate cycling (i.e. cycling between $10^{-3}$ and $10^{-2} \mathrm{~s}^{-1}$ ) and strain rate increase tests were performed. The amorphous nature of the alloy was confirmed using transmission electron microscopy (TEM), as shown in Fig. 2. The TEM sample was prepared by chemical milling.

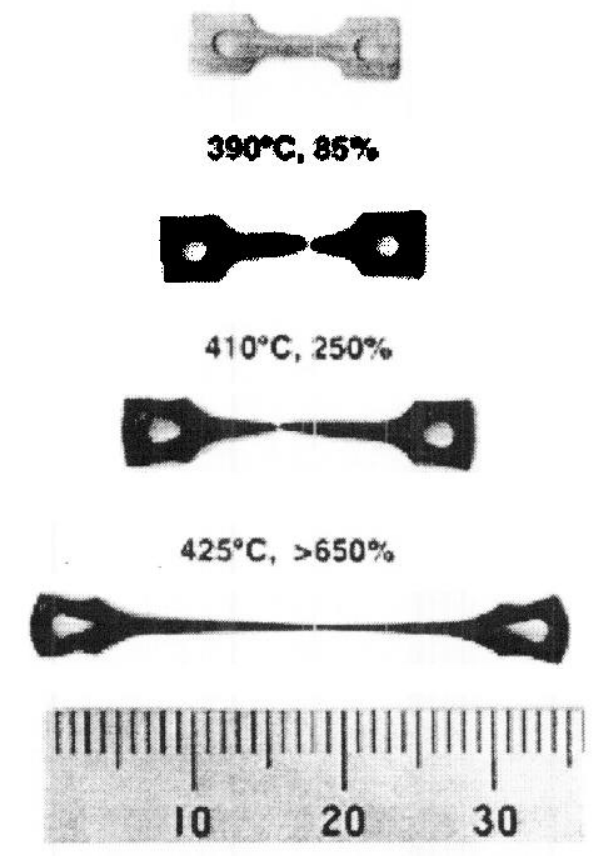

Fig. 1 Amorphous samples fractured at different temperatures. Sample necking is apparent. An untested sample is included for comparison.

\section{RESULTS AND DISCUSSION}


The stress-strain curves for the alloy at different temperatures at a strain rate of $10^{-2} \mathrm{~s}^{-1}$ is shown in Fig. 3. A yield drop phenomenon is readily observed at low temperatures, and in particular at 663 and $683 \mathrm{~K}$. In fact, at $663 \mathrm{~K}$ the yield drop is $750 \mathrm{MPa}$ (i.e. from $1600 \mathrm{MPa}$ to $850 \mathrm{MPa}$ ), which is about the same magnitude as its 'normal' yield strength $(\sim 850 \mathrm{MPa})$. The yield drop phenomenon has also been observed and studied by Kawamura et al [5] during testing of a $\mathrm{Zr}_{65} \mathrm{Al}_{10} \mathrm{Ni}_{10} \mathrm{Cu}_{15}$ metallic glass in the supercooled liquid region. They attributed the yield drop to a 'transient phenomenon', but the associated concurrent change of atomic structure associated with the phenomenon was not given.

It is noted that similar phenomena have also been observed in the homogeneous flow of glassy polymers and in the plastic deformation of crystalline metal alloys. In the case of glassy polymers, this behavior is associated with the stress-effected, segmental chain displacements and the preferential alignment of the long axis of the molecules along the tensile axis. Both chain displacements and molecular alignments are achievable by the nucleation and propagation of 'double kinks' along the chain axis. By contrast, in crystalline metal alloys, it

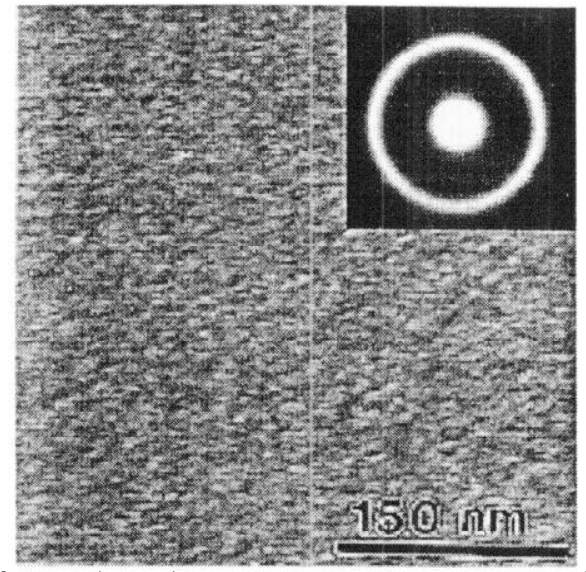

results from the locking of dislocations by solute atoms, e.g. Cottrell locking [28], or the shearing of coherent precipitates by dislocations [29]. For metallic glasses, however, neither the theory for glassy polymers or for crystalline metals appears to be applicable. Kawamura et al [30] argued that the yield drop was caused by an initial increase in atomic mobility at high strain rates, but, upon yielding, the atomic mobility decreases and structure relaxes. However, the exact physical process that leads to the observed yield drop is still unclear [30]. Structural clustering and chemical short range ordering are expected to impede the propagation of shear bands and may be responsible, in part, for the yield drop.

Fig. 2 Transmission electron micrograph shows the amorphous nature of the alloy.

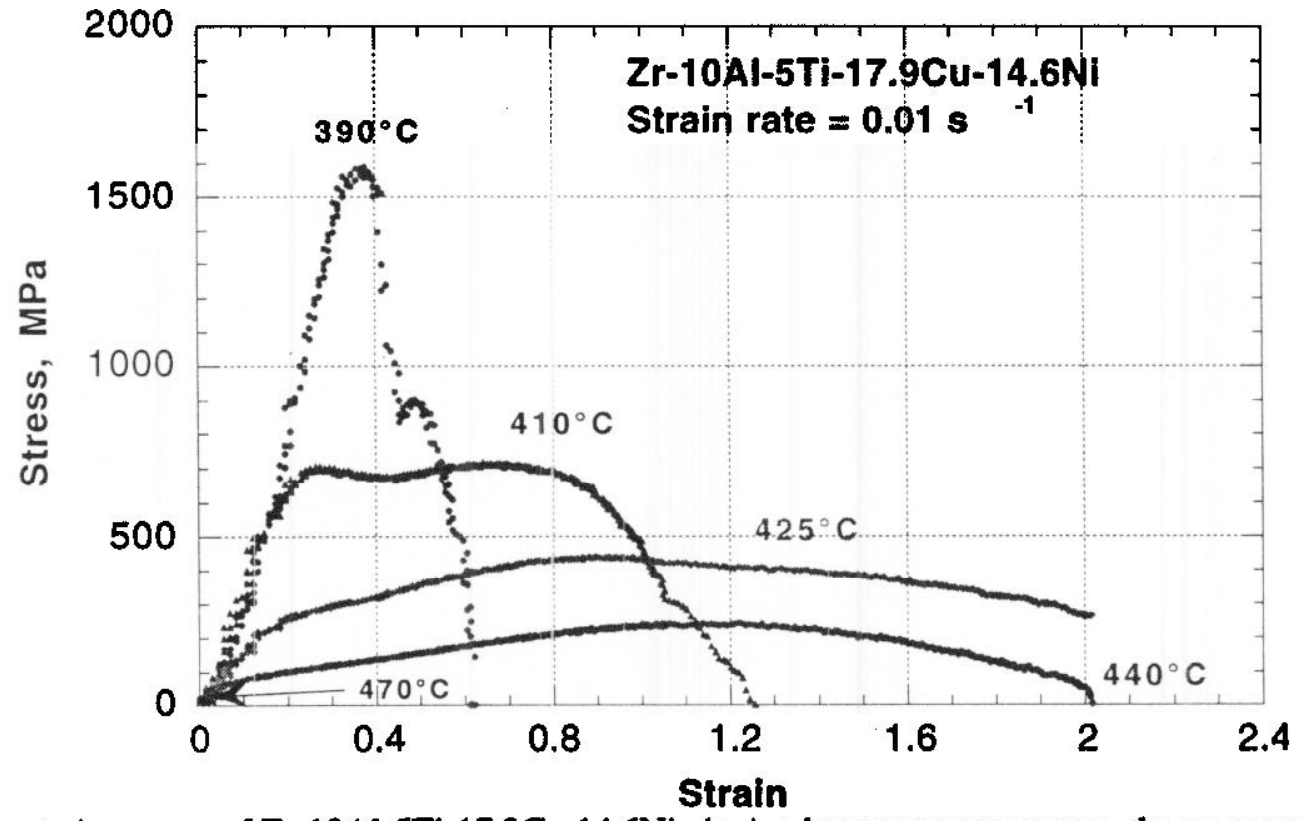

Fig. 3 Stress-strain curves of $\mathrm{Zr}-10 \mathrm{Al}-5 \mathrm{Ti}-17.9 \mathrm{Cu}-14.6 \mathrm{Ni}$ obtained at temperatures near the supercooled liquid region. The yield drop phenomenon is readily seen, especially at low temperatures. 
The yield drop phenomenon disappears at a strain rate of $10^{-2} \mathrm{~s}^{-1}$ and at temperatures higher than $683 \mathrm{~K}$. In these temperatures, there is an initial hardening, followed by a gradual decrease in flow stress until final fracture. The fracture strain increases with increasing test temperature and reaches a maximum value of $2.0(\sim 650 \%$ elongation) at 698 and $713 \mathrm{~K}$. At $743 \mathrm{~K}$, which is above the crystallization temperature $(729 \mathrm{~K})$, the alloy becomes extremely brittle; in fact, the test sample failed at the location of the loading pin. It is noted that samples, which were deformed in the supercooled liquid region, exhibit gradual necking, as shown in Fig. 2 . In fact, some samples necked down nearly to a point. The final decrease in flow stress is, therefore, not a result of softening, but reduction in load bearing. This fracture appearance is different from that observed in a $\mathrm{Zr}_{65} \mathrm{Al}_{10} \mathrm{Ni}_{10} \mathrm{Cu}_{15}$ metallic glass [5], in which uniform deformation was observed. The difference may be caused by the fact that the samples used by Kawamura et al were very thin $(0.02 \mathrm{~mm})$. As a result, the samples were subject to a plane stress condition.

It is evident in Fig. 3 that both the flow stress and fracture strain are extremely sensitive to testing temperature. For example, with only a $15 \mathrm{~K}$ difference in testing temperature, the flow stress drops from $700 \mathrm{MPa}$ at $683 \mathrm{~K}$ to about $400 \mathrm{MPa}$ at $698 \mathrm{~K}$. The tensile elongation is almost tripled $(230 \%$ to $630 \%)$. The flow stresses are generally quite high; for example, at even $713 \mathrm{~K}$ the flow stress is about $200 \mathrm{MPa}$. A high flow stress was also observed in another superplastic $\mathrm{Zr}_{65} \mathrm{Al}_{10} \mathrm{Ni}_{10} \mathrm{Cu}_{15}$ metallic glass, which was over $100 \mathrm{MPa}$ [6]. These values are considerably higher than the flow stresses generally observed in metals or ceramics exhibiting superplasticity or extended ductility [31]. Flow stresses for a superplastic metal or ceramic are typically lower than $35 \mathrm{MPa}$. Technologically, a high flow stress can cause fast wear of the forming dies.

To characterize the deformation behavior, strain rate cycling tests were carried out at $683 \mathrm{~K}$ to measure the strain rate sensitivity value. The result is shown in Fig. 4; the values of strain rate sensitivity $m$ in equation $\dot{\varepsilon}=K \cdot \sigma^{m}$, where $\dot{\varepsilon}$ is the strain rate, $\sigma$ is the flow stress, and $\mathrm{K}$ is a constant, were measured by strain rate cycling between $10^{-2}$ and $7 \times 10^{-3} \mathrm{~s}^{-1}$. There is no steady state region after each cycle, making it difficult to determine accurately the strain rate sensitivity value. This difficulty may be associated with structural instabilities during testing. It is noted that an external applied stress can promote crystallization in amorphous alloys [32]. Thus, despite the fact that $683 \mathrm{~K}$ is below the crystallization temperature, it is believed that some nano-scale, crystallized phase already evolved during the course of the test. The presence of nanocrystalline phases can significantly affect the mechanical properties of a metallic glass. For example, Busch et al [18] recently showed that the presence of crystalline phases increases the viscosity of a $\mathrm{Zr}_{46.75} \mathrm{Ti}_{8.25} \mathrm{Cu}_{7.5} \mathrm{Ni}_{10} \mathrm{Be}_{27.5}$ metallic glass. This observation is also consistent with the results of Kim et al $[33,34]$ who reported that the fracture strength of an amorphous $\mathrm{Al}_{88} \mathrm{Ni}_{10} \mathrm{Y}_{2}$ was doubled when the alloy was crystallized and contained 5-12 nm-size Al particles. Thus, in the present strain rate cycle test, continuous strengthening is proposed to be a result of the continuous precipitation of nanocrystals in the amorphous matrix. In fact, this is also reflected by a slight increase in stress after the initial yield drop (strain $>0.4$ ) shown in Fig. 4.

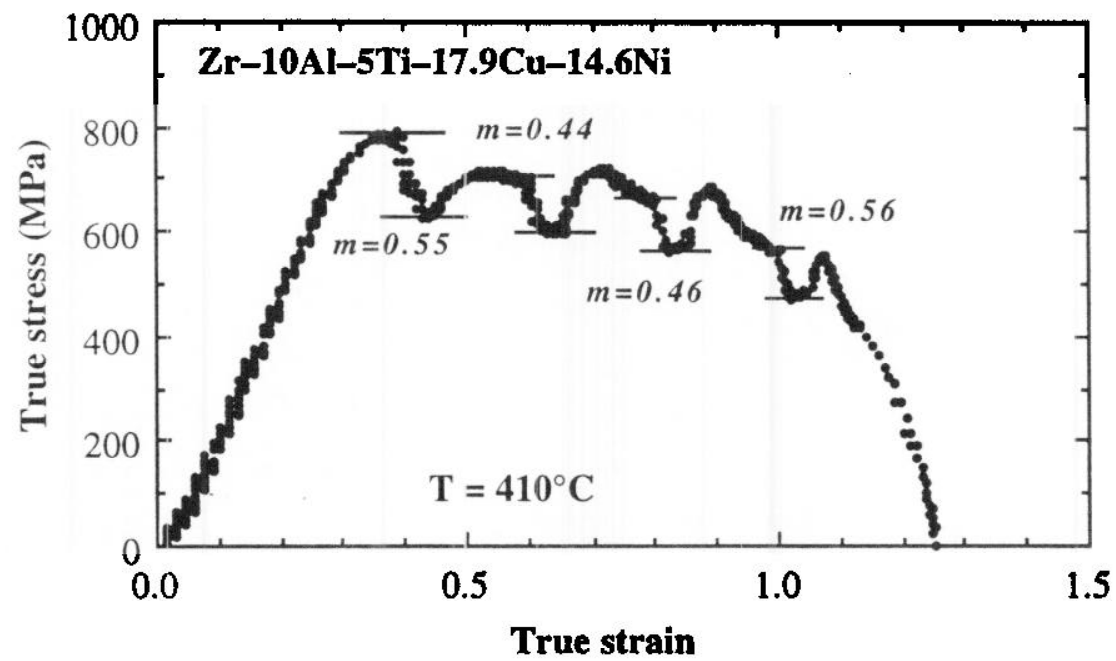

Fig. 4 Strain rate cycling test at $683 \mathrm{~K}$ showing that the strain rate sensitivity value is only $0.45-0.55$.

As shown in Fig. 4, after each strain rate decrease, except for the first one, there is no steady-state flow region. The gradual decrease in flow stress after decreasing the strain rate results from sample necking. Data from Fig. 4 indicate that the onset of sample necking occurs at a strain of approximately 0.8 , which is consistent with the results observed in single-strain-rate tests (Fig. 3). The fracture obtained in the strain rate cycling test is also similar to that obtained in a constant strain rate test.

It is worth noting that from Fig. 4 the "apparent" strain rate sensitivity for the present $\mathrm{Zr}-10 \mathrm{Al}-5 \mathrm{Ti}-17.9 \mathrm{Cu}-$ $14.6 \mathrm{Ni}$ alloy is computed to be about 0.5 . Although structural instability can contribute to some variations in determining the "true" strain rate sensitivity value, its influence is not expected to be sufficiently great to imply a 
"true" strain rate sensitivity value of as high as one. In other words, the present alloy does not behave like a Newtonian fluid. The non-Newtonian behavior may be caused by the fact that the structure of the alloy in the supercooled liquid region is thermally unstable. Upon thermal exposure, and particularly under an external applied stress, the amorphous structure tends to crystallize and results in a mixture of crystalline and amorphous structure. Experimentally, it is challenging to examine the structure of a superplastically deformed specimen, primarily because tested samples necked down to nearly a point. Sample preparation for either $\mathrm{x}$-ray diffraction or TEM study is, therefore, difficult. Moreover, the present experiments were performed in air, which resulted serious oxidation on test samples (see next section). The presence of a diffraction pattern may be simply indicative of oxide formation.

However, if an alloy indeed has a mixed crystalline-plus-amorphous structure, to a first approximation, the total deformation rate can be expressed by:

$$
\dot{\varepsilon}_{\text {toral }}=\left(1-f_{v}\right) \cdot \dot{\varepsilon}_{a m}+f_{v} \cdot \dot{\varepsilon}_{c r y}
$$

where $\dot{\varepsilon}_{\text {total }}$ is the total strain rate, $\dot{\varepsilon}_{\text {am }}$ and $\dot{\varepsilon}_{\text {cry }}$ are the strain rates caused by the amorphous and crystalline phases, respectively, and $f_{\mathrm{v}}$ is the volume fraction of the crystalline phase. Since the plastic flow of an amorphous alloy can be described by $\dot{\varepsilon}_{\text {am }}=A \sigma$, and the plastic flow of a nanocrystalline, superplastic alloy can be described by $\dot{\varepsilon}_{\text {cry }}=\mathrm{B} \sigma^{2}$, where $\sigma$ is the flow stress, and A and B are material constants, Equation (1) can be rewritten as:

$$
\dot{\varepsilon}_{\text {total }}=\left(1-\mathrm{f}_{\mathrm{v}}\right) \cdot \mathrm{A} \sigma+\mathrm{f}_{\mathrm{v}} \cdot \mathrm{B} \sigma^{2}
$$

It is obvious that the strain rate sensitivity, which is the reciprocal of the stress exponent, would be between 0.5 , the value for grain boundary sliding mechanism in fine-grained crystalline material, and unity, the value for Newtonian viscous flow.

It is interesting to comment on the drastic reduction in tensile elongation from $650 \%$ at $713 \mathrm{~K}$ to virtually zero at $743 \mathrm{~K}$. A temperature of $743 \mathrm{~K}$ is above the crystallization temperature of the alloy $(\sim 729 \mathrm{~K})$. At this temperature, the alloy has a nanocrystalline structure consisting of many intermetallic phases. Conventional wisdom suggests that an ultrafine grain size alloy should have a large tensile elongation, presumably resulting from extensive grain boundary sliding. However, it must be pointed out that, in the case of grain boundary sliding, sliding strain must be properly accommodated either by diffusional flow or by dislocation slip (e.g., climb or glide) across neighboring grains, in order to prevent cavitation and, thus, fracture. However, dislocation slip in an ordered, multicomponent intermetallic compound is difficult at temperatures near $T_{\mathbf{x}}$. Also, diffusional processes are not expected to be sufficiently fast to accommodate sliding strains at strain rates of $\sim 10^{-2} \mathrm{~s}^{-1}$. This offers an explanation for a high $m$ value but low tensile elongation in metallic glasses at temperatures near $T_{\mathbf{x}}$. It is worth noting that, no accommodation is needed for pure Newtonian flow.

\section{Microstructure and Fracture surface}

$\mathrm{Zr}$-based metallic glasses have poor oxidation resistance. For example, the cross-section microstructure in the vicinity of the fracture surface of the sample tested at $713 \mathrm{~K}$ and $10^{-3} \mathrm{~s}$ is shown in Fig. 5 . As expected, the internal structure is featureless. However, an oxide layer, estimated to be about $4 \mu \mathrm{m}$ thick, is present. The layer was extremely brittle and non-uniform in thickness. The uneven thickness suggests that oxide layer was fractured and new surface was continuously created, but immediately oxidized, as a result of sample stretching. The formation and fracturing of oxide layer is not expected to affect significantly the flow stress since the layer thickness is relatively low. It has also little effect on the ductility, since the material is not notch sensitive in the supercooled liquid region, except in the final stage of deformation.

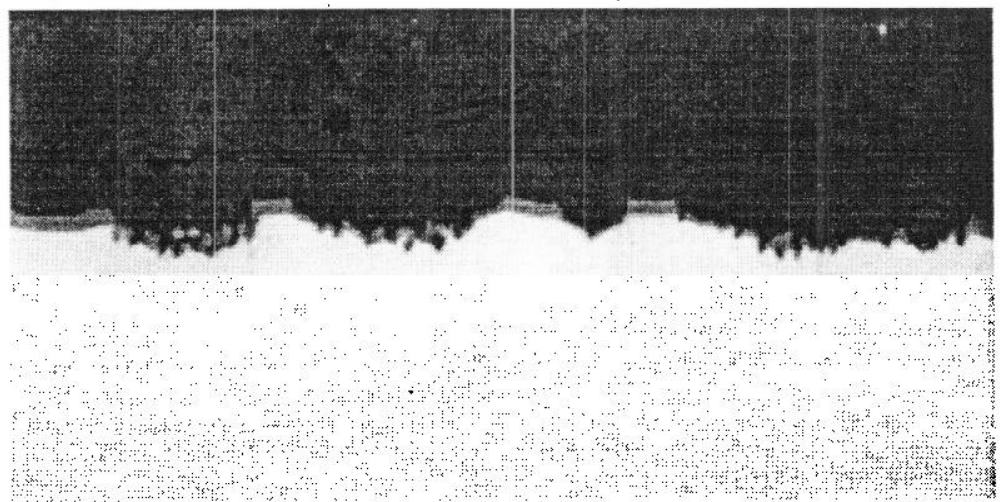

Fig. 5 Cross sectional view of the sample fractured at $713 \mathrm{~K}$ and $10^{-3} \mathrm{~s}^{-1}$. A non-uniform oxide layer is readily seen. The maximum thickness is about $4 \mu \mathrm{m}$. 
It is well known that, at room temperature, the fracture surface of a metallic glass exhibits a vein pattern (Fig. 6), as a result of the sudden release of elastic energy at fracture [2]. Also, sample does not show any necking after fracturing. These are typical fracture characteristics for metallic glasses deformed inhomogeneously. In contrast, metallic glasses show strong resistance to necking in the supercooled liquid region; this is readily observed in Fig. 1. The strong necking resistance is apparently a result of high strain rate sensitivity.

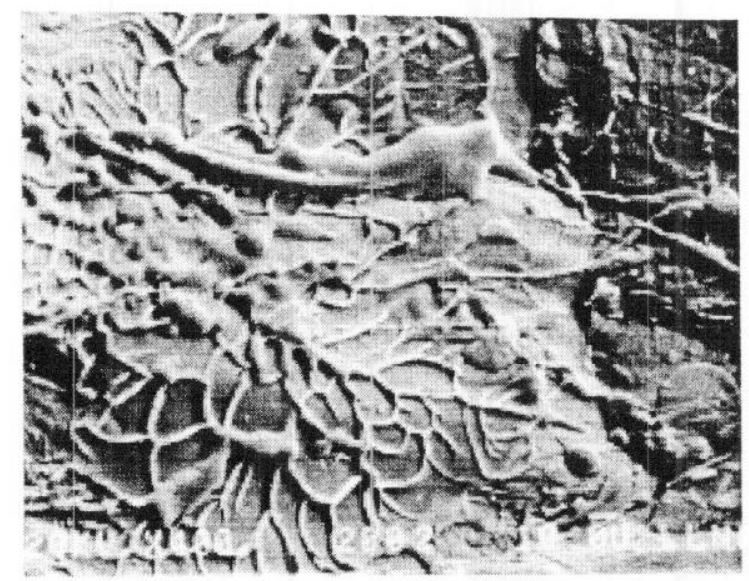

Fig. 6 Vein pattern formed on the fracture surface of amorphous of $\mathrm{Zr}-10 \mathrm{Al}-5 \mathrm{Ti}-17.9 \mathrm{Cu}-14.6 \mathrm{Ni}$ tested in tension at room temperature. Melted droplets are readily seen.

The fracture surface of the sample tested at $663 \mathrm{~K}$ and at a strain rate of $10^{-2} \mathrm{~s}^{-1}$ is shown in Fig. 7. It appears that vein pattern persists even at $663 \mathrm{~K}$, where homogeneous deformation prevails. However, a close examination of Fig. 7 indicates that the pattern is actually different from that observed at room temperature. Specifically, the ridges between voids are much higher and there is no indication of melting. In addition, large voids were present. These voids were obviously developed prior to the final fracture of the sample; they were formed under a triaxial stress. As shown in Fig. 1, the sample exhibits considerable necking. The reduction in area for the $663 \mathrm{~K}$ sample was about $96 \%$. At $683 \mathrm{~K}$ sample fractured nearly to a chisel point (reduction in area $>99 \%$ ). The fracture surface, as shown in Fig. 8, reveals a ductile dimple fracture with the absence of vein pattern. The brittle-to-ductile transition from inhomogeneous to homogeneous deformation is clearly revealed by the fracture surface appearance.

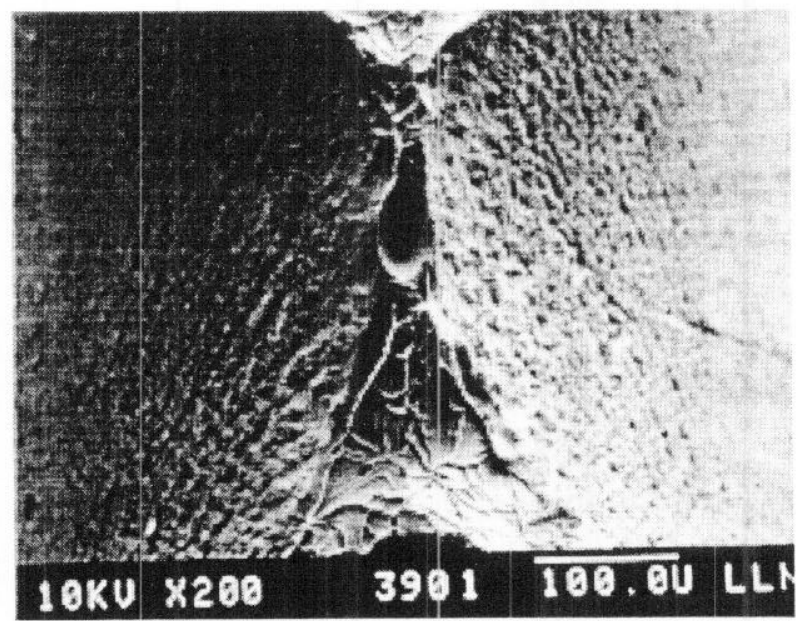

Fig. 7 Fracture surface of the sample tested at $663 \mathrm{~K}$ and at a strain rate of $10^{-2} \mathrm{~s}^{-1}$. 


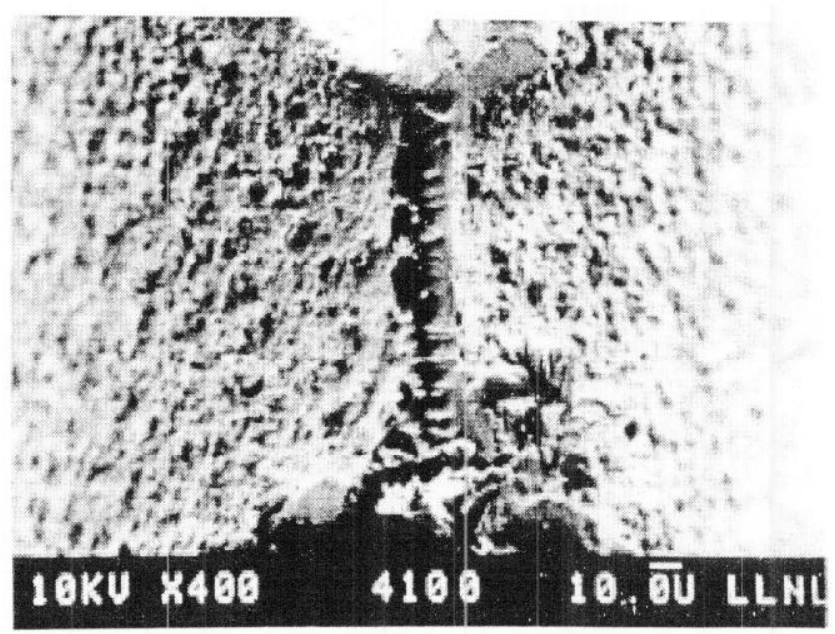

Fig. 8 Fracture surface of the sample tested at $683 \mathrm{~K}$ and at a strain rate of $10^{-2} \mathrm{~s}^{-1}$ reveals a ductile dimple appearance with the absence of vein pattern.

\section{SUMMARY}

The deformation behavior of a $\mathrm{Zr}-10 \mathrm{Al}-5 \mathrm{Ti}-17.9 \mathrm{Cu}-14.6 \mathrm{Ni}$ metallic glass was characterized in the supercooled liquid region. The alloy was observed to exhibit a large tensile elongation in this region; a maximum tensile elongation of over $600 \%$ was recorded at $698-713 \mathrm{~K}$ at a high strain rate $10^{-2} \mathrm{~s}^{-1}$. The superplastic properties, e.g. flow stress and elongation, are found to be very sensitive to testing temperature. As a result of structural instabilities it is difficult to determine the "true" strain rate sensitivity value. Despite this difficulty, experimental results indicated that the alloy does not behave like a Newtonian fluid $(m=1)$. It is suggested that the non-Newtonian behavior is caused by the concurrent crystallization of the amorphous structure during deformation; a mixed crystalline-plus-amorphous structure was actually tested. At temperatures above the crystallization temperature, in spite of having a nanocrystalline structure, the alloy exhibit limited ductility. This is a result of poor strain accommodation at grain triple junctions. Microstructural examination of the fracture sample is now underway.

\section{ACKNOWLEDGMENT}

This work was performed under the auspices of the U.S. Department of Energy by Lawrence Livermore National Laboratory under contract No. W-7405-Eng-48. The authors would like to thank Dr. Luke Hsiung for his contribution of Fig. 2.

\section{REFERENCES}

1. W. Klement, R. Willens, and P. Duwez, Nature, 187 (1960) 869.

2. C.T. Liu, et al., Mater. Trans. A, 29A (1998) 1811.

3. K. Hashimoto, N. Kumagai, H. Yoshioka, H. Habazaki, A. Kawashima, K. Asami, and B.-P. Zhang, Mater. Sci. Eng., A133 (1991) 22.

4. D.G. Morris, in Proc. Sth Int'l Conf. on Rapidly Quenched Metals, p. 1775, edited by S. Steeb and H. Warlimont, Elsevier Science Publishers B.V., 1985.

5. Y. Kawamura, T. Shibata, A. Inoue, and T. Masumoto, Scr. Mater., 37 (1997) 431.

6. Y. Kawamura, T. Nakamura, and A. Inoue, Scr. Mater., 39(3) (1998) 301.

7. Y. Kawamura, T. Nakamura, A. Inoue, and T. Masumoto, Mater. Trans. JIM, 40(8) (1999) 794.

8. T. Masumoto and R. Maddin, Mater. Sci. Eng., 19(1) (1975) 1.

9. H. Chen, Y. He, G.J. Shiflet, and S.J. Poon, Nature, 367(6463) (1994) 541.

10. F. Spaepen, Acta Metall., 25 (1977) 407.

11. A.S. Argon, Acta Metall., 27 (1979) 47.

12. J.C.M. Li, in Proc. 4th Int'l Conf. on Rapidly Quenched Metals, p. 1335, edited by T. Masumoto and K. Suzuki, Japan Institute of Metals, Sendai, Japan, 1982.

13. A.L. Mulder, R.J.A. Derksen, J.W. Drijver, and S. Radelaar, in Proc. 4th International Conf. on Rapidly Quenched Metals, p. 1345, edited by T. Masumoto and K. Suzuki, Japan Institute of Metals, Sendai, Japan, 1982.

14. A.I. Taub and F.E. Luborsky, Acta Metall, 29 (1981) 1939.

15. H. Eyring, J. Chem. Phys., 4 (1936) 283.

16. C. Homer and A. Eberhardt, Scr. Metall., 14 (1980) 1331. 
17. V.A. Zelenskiy, A.S. Tikhonov, and A.N. Kobylkin, Russian Metallurgy, 4 (1985) 152.

18. R. Busch, E. Bakke, and W.L. Johnson, Acta Mater., 46(13) (1998) 4725.

19. V.A. Khonik and V.A. Zelenskiy, Phys. Met. Metall., 67(1) (1989) 196.

20. K. Csach, Y.V. Fursova, V.A. Khonik, and V. Ocelik, Scr. Mater., 39(10) (1998) 1377.

21. C.P. Ashdown, Y. Zhang, and N.J. Grant, Int'l J. Powder Metall., 23(1) (1987) 33.

22. H. Brandt, J. Gossing, G. Mathiak, and H. Neuhauser, Z. Metallkd., 84(4) (1992) 273.

23. D.L. Wang, Q.P. Kong, and J.P. Shui, Scr. Metall. Mater., 31(1) (1994) 47.

24. J. Deng, D.L. Wang, Q.P. Kong, and J.P. Shui, Scr. Metall. Mater., 32(3) (1995) 349.

25. K. Higashi, T. Mukai, A. Uoya, A. Inoue, and T. Masumoto, Mater. Trans. JIM, 36(12) (1995) 1467.

26. A. Uoya, T. Shibata, K. Higashi, A. Inoue, and T. Masumoto, J. Mater. Res., 11(11) (1996) 2731.

27. T.G. Nieh, J. Wang, J. Wadsworth, T. Mukai, and C.T. Liu, in Symposium on Bulk Metallic Glasses, edited by W.L. Johnson, C.T. Liu, and A. Inoue, Materials Research Soc., Pittsburgh, PA, 1999. -in press

28. A.H. Cottrell and B.A. Bilby, Proc. Phys. Soc. (London), 62A (1949) 49.

29. T.G. Nieh and W.D. Nix, Metall. Trans., 17A (1986) 121.

30. Y. Kawamura, T. Shibata, A. Inoue, and T. Masumoto, Mater. Trans. JIM, 40(4) (1999) 335.

31. T.G. Nieh, O.D. Sherby, and J. Wadsworth, Superplasticity in Metals and Ceramics, Cambridge University Press, Cambridge, UK, 1997.

32. R. Maddin and T. Masumoto, Mater. Sci. Eng., 9 (1972) 153.

33. Y.H. Kim, A. Inoue, and T. Masumoto, Mater. Trans. JIM, 31 (1990) 747.

34. Y.H. Kim, K. Hiraga, A. Inoue, T. Masumoto, and H.H. Jo, Mater. Trans. JIM, 35(5) (1994) 293. 